\title{
VIAJE DEL RECUERDO. FRAGMENTOS DE LA HISTORIA DEL FERROCARRIL AL PACÍFICO DE COSTA RICA
}

\author{
Memory trip. \\ Fragments of the history of the railroad to the Pacific of Costa Rica
}

\author{
Javier Agüero García \\ Universidad de Costa Rica, Costa Rica \\ jav_aguero@hotmail.com
}

\begin{abstract}
Recibido: $16-10-2019$
\end{abstract}
Aprobado: 29-11-2019

Javier Agüero García es egresado del Programa Latinoamericano de Doctorado en Educación, UCR. Magister Scientiae en Historia, UCR y egresado de la Licenciatura en Docencia de la UNED. Excoordinador de la Sección de Historia y Geografía de la Sede de Occidente. Profesor de la Cátedra de Historia de la Cultura de la Escuela de Estudios Generales de la Sede Rodrigo Facio y de la Sección de Historia y Geografía del Departamento de Ciencias Sociales de la Sede de Occidente. $\mathrm{Ha}$ impartido los cursos de Historia de la Cultura en las opciones regular y seminario participativo, Historia de las Instituciones de Costa Rica, Historia Antigua Universal, Historia Moderna Universal, Historia Contemporánea Universal, Teoría de la Historia Económica, Temas de Historia Económica en Historia Universal y Formación Ciudadana.

\section{RESUMEN}

El presente ensayo aborda aspectos del Ferrocarril al Pacífico, dentro de la perspectiva histórica, con la finalidad de valorar su significado patrimonial, tanto en la cultura como el ámbito institucional. Se inicia con la descripción de la etapa constructiva de esta importante vía de comunicación, proceso iniciado en 1897; se pasa luego a la electrificación, como piedra angular de la modernización; para finalmente pasar al abordaje de las locomotoras, verdaderos caballos de acero que hicieron posible el transporte de mercancías y de pasajeros. e concluye con una reflexión acerca del significado de la empresa ferroviaria estatal, baluarte del desarrollo económico, social e institucional del país, resumida en los atributos de rapidez, economía, seguridad y eficiencia.

Palabras clave: Patrimonio; Ferrocarriles; Pacífico; Orotina; Costa Rica

\section{ABSTRACT}

This essay addresses aspects of the Railroad to the Pacific within the historical perspective in order to assess its heritage significance, both in culture and in the institutional field. It begins with the description of the construction stage of this important means of transport, a process started in 1897; it is then passed to electrification, as the cornerstone of modernization; to finally move on to the approach of locomotives, true steel horses that made possible the transport of goods and passengers. It concludes with a reflection on the meaning of the state railway company, bastion of the economic, social and institutional development of the country, summarized in the attributes of speed, economy, security and efficiency.

Keywords: Heritage; Railroad; Pacífico; Orotina; Costa Rica 


\section{Introducción}

En 2017, la locomotora Siemens 130 llegó a Orotina por última vez, fue transportada, en dos automotores, por la carretera 27, desde horas de la madrugada desde San José. Atrás quedaron los viajes de esta máquina eléctrica, fabricada en Alemania, que impulsaba, con su poderosa tracción, los vagones de carga y de pasajeros. Luego de una exitosa campaña llevada a cabo por la Asociación para la preservación del Patrimonio Cultural de Orotina (ADEPPCO), la locomotora descansará después de que este caballo de acero brindará sus servicios por casi cuarenta años. Su lugar será ahora un sitio reservado contiguo a la estación ferroviaria ubicada en el cantón alajuelense reconocido por la producción de frutas.

Detrás de este viaje por el pavimento entre la capital y Orotina, para llevar a la máquina herrumbrada y desteñida, otrora pintada con los vistosos colores blanco azul y rojo, subyace una historia que va más allá de las doce horas que tardó su traslado, gracias al empeño tesonero y a la colaboración de los servidores del Instituto Costarricense de Ferrocarriles (INCOFER) y de ADEPPCO. Para el presidente de esta agrupación comunal, Giovanni Castaldini, este gesto constituye un tributo en aras de preservar la memoria histórica que invita a la ciudadanía a asomarse a través de una ventana para contemplar el pasado y así recordar vivencias individuales y colectivas que coinciden con la coyuntura de mayor prosperidad de Orotina (Castro, 2017). No en vano, un tren está estampado en su escudo cantonal.

Imagen 1. Escudo cantonal de Orotina

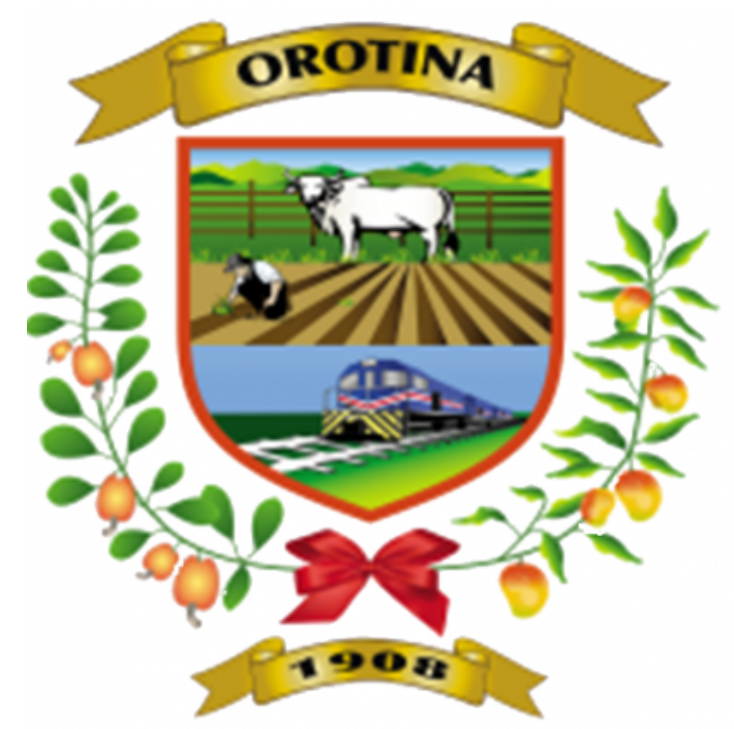

Fuente: Imagen tomada con fines didácticos de https://www.google.com 
La 130, -como comúnmente se le llama a la locomotora de cita-forma parte del patrimonio institucional de Costa Rica, enraizado en un titánico proyecto de construcción de un ferrocarril, iniciado en 1897, que conectara San José con el litoral Pacífico.

En este ensayo se aborda el tema del Ferrocarril Costarricense al Pacífico, desde una perspectiva interesada en resaltar el patrimonio institucional, con el fin de analizar su significado a través de su evolución, inserto en el desarrollo institucional del país. Para tal efecto se estudian los tópicos siguientes:

- la construcción de una ruta alterna a la controlada por la Compañía Bananera;

- el proceso de modernización, merced a la electrificación; y

- las locomotoras como testigos de la modernización.

Además de las fuentes secundarias, se consultarán documentos valiosos en cuanto a información contenida en periódicos, fotografías y vídeos.

\section{Hacia la construcción de una vía alterna}

La inserción de Costa Rica al mercado mundial a partir de la década de 1840, hizo imperiosa la construcción de caminos que posibilitaran el contacto con los puertos de salida del producto de exportación; preocupación compartida por los países latinoamericanos deseos de colocar, en el extranjero, sus productos comerciales, "... durante la vertiginosa expansión del capitalismo industrial..." (Cardoso y Pérez, 1982, p. 105).

Hacia el Caribe se construyó la primera vía férrea completa con lo que se materializó el sueño del arquitecto del Estado costarricense, Braulio Carrillo, quien desde el decenio de 1830 añoraba conectar el valle Central con Matina; que a su vez, posibilitara el contacto con mercados europeos compradores de café. Su construcción primero consumió esfuerzos económicos del gobierno de la república, "en el esfuerzo estatal desesperado" (Murillo, 1995, p. 30); pero al no lograrse gran avance, ante la carencia de recursos, se dio paso a la firma del contrato Soto-Keith en 1884; para así brindar el impulso final al proyecto constructivo. Al mismo tiempo, se cedió el control y administración del ferrocarril, junto con el derecho del uso del $8 \%$ del territorio nacional a una empresa foránea. Además se exoneró a la concesionaria del pago de impuestos. Todas estas cláusulas contaban con un tiempo de disfrute de noventa y nueve años. 
Al término de veinte años, el ferrocarril inaugurado formalmente en 1891, en medio de constantes reclamos del empresario Minor C. Keith quien reiteradamente, no se cansó de solicitar mayores prebendas por parte del Estado costarricense, aduciendo dificultades por lo agreste de la geografía, causantes del aumento en los costos finales no contemplados en la contrata rubricada en 1884 (Quesada, 1983, p. 109).

Pocos meses después de celebrarse un baile en honor al empresario estadunidense constructor del ferrocarril, Keith solicitó al Congreso Constitucional la suma de $£ 200.000$ como indemnización por concepto de pérdidas ocasionadas por las condiciones naturales adversas. Esta petitoria generó la oposición encarnizada de sectores organizados y de figuras políticas; entre los primeros, destaca la Asociación de Artesanos de San José, quienes apelaban enérgicamente aduciendo que el Estado costarricense no tenía culpa de las supuestas pérdidas incurridas por el empresario, pues fueron contingencias naturales las responsables. Aunado a estas razones, merece mencionarse la posición expuesta por el abogado Pedro Pérez Zeledón, quien en diferentes artículos se refirió en detalle a las finanzas del ferrocarril, además de hacer notar las gestiones de Keith en Londres, conducentes a recibir la mayor cantidad de dinero posible. Finamente, aunque el Estado solo reconoció al empresario menos de la cuarta parte de la suma pretendida por el concesionario, la soberanía del país resultó seriamente comprometida (Stewart, 1991, pp. 119-133).

La empresa ferroviaria recibió el nombre de Northern Railway Company, subsidiaria de la United Fruit Company, cuando esta última se fundara en Boston en 1899, por parte de los empresarios estadounidenses Minor C. Keith y Andrew W. Preston (Araya, 1982, p. 52; Cardoso y Pérez, 1983, p. 279); y con ello

...El consorcio [...] creó en la región del mar Caribe una gigantesca red de producción de plátano [...] que incluía plantaciones en el trópico, viviendas, hospitales, ferrocarriles, líneas telegráficas, puertos y la flota de barcos de vapor más numerosa del mundo, la Gran Flota Blanca...(Bucheli y Read, 2017, p. 287).

La concesionaria ferrocarrilera funcionó bajo la lógica empresarial colocando como prioridad los intereses del negocio frutero bananero; dejando de lado el transporte del café, de ahí que pusiera oídos sordos a los reclamos en torno a la 
deficiencia del servicio y a las altas tarifas. Ante estas vicisitudes, las autoridades gubernamentales empezaron a valorar la posibilidad de construir un nuevo ferrocarril con destino al Pacífico. A partir de 1893 se revivió la iniciativa del proyecto que dotara de una ruta concluida acorde con las necesidades de los comerciantes y beneficiadores del grano de oro; que pudiera superar en demasía los ingentes esfuerzos del decenio de 1850, cuando se tendieron unas líneas férreas, el "burrrocarril", entre Barranca y Puntarenas, un rudimentario sistema de transporte donde la carga era arrastrada por la fuerza de mulas (Stewart, 1991, p. 19).

Luego de vencer los desafíos propios de la búsqueda de contenido presupuestario, en 1897, bajo el gobierno de Rafael Yglesias Castro, se inició la construcción del Ferrocarril al Pacífico, en una coyuntura caracterizada por el fomento del comercio por parte del ente estatal (Jara, 2014, p. 417). En ese mismo año se rubricó el contrato con John Stephen Casement para que se hiciera cargo de la obra, bajo cláusulas muy distintas con respecto a las de la contrata Soto-Keith que cedía tierras y derechos a la empresa extranjera. El documento de cita, firmado para la construcción de una vía alterna suponía un compromiso adquirido por el Estado costarricense exclusivamente en materia de edificación y, en ningún momento se incorporaron elementos en menoscabo de la soberanía nacional, como sucedió con la vía hacia el Caribe.

Con gran empeño iniciaron las obras en 1897, siguiendo un trazado correspondiente a un vetusto camino colonial que a su vez remitía a la época indígena (Molina, 2005, p. 518). El avance de la obra estuvo limitado por las crudas condiciones topográficas y climáticas. En 1902, además del ramal de Alajuela, se habían tendido las líneas férreas entre la ciudad capital y Santo Domingo de San Mateo -hoy Orotina (Noriega, 1923)- sitio donde se construyó una terminal provisional. Pese al nivel de progreso alcanzado, al incluir la construcción del imponente puente sobre el río Grande de Atenas, la obra adolecía de un atraso considerable, derivada de la caída de los precios internacionales del café (Hall, 1982, p. 63). De ahí que se optara por préstamos adicionales para hacerle frente a la construcción del tramo faltante, solventado inicialmente con un primitivo camino de carretas, vía Esparza. De no contarse con recursos económicos frescos, el ferrocarril quedaría condenado al uso de una "vía mixta", con locomotoras y carretas, poniendo en franca desventaja al ferrocarril del Estado frente al de la transnacional (Ulloa, 1998, p. 80). 
Imagen 2. Construcción de Ferrocarril al Pacífico

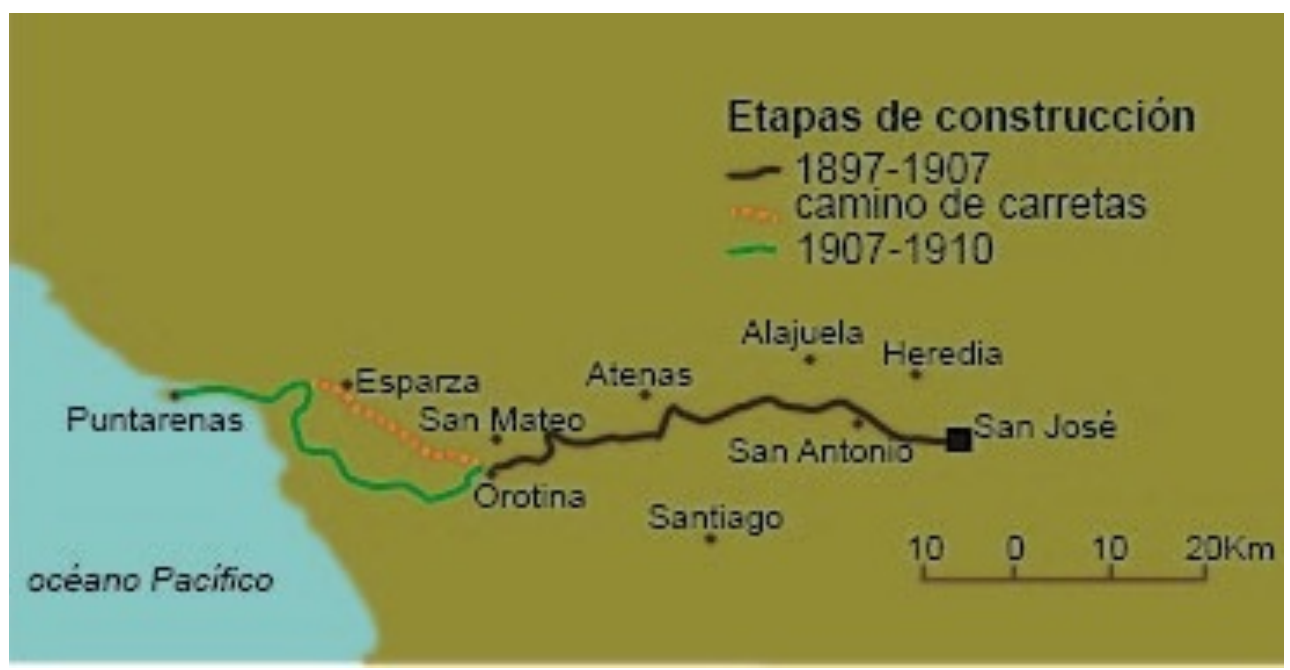

Fuente: Elaboración propia a partir de: Segarra, José y Juliá, Joaquín. (1907). Excursión por América, Costa Rica. San José: Imprenta de Avelino Alsina., pp. 511-512. Ulloa, Herberth. (1997). El Ferrocarril Costarricense al Pacífico: construcción e incidencias (1897-1932). San José: ECR., pp. 80-85.

Al respecto, en 1907, José Segara y Joaquín Juliá, dos viajeros españoles tomaron el tren desde el valle Central hacia Orotina, sitio donde provisionalmente se levantaba una modesta estación. Cuando se llegaba allí, percibieron

...el calor de horno; y al trote de dos infelices jamelgos de alquiler, nos entregamos a la fatiga y al polvo de la cansada "carretera» carretera que conduce a Esparta: cuatro horas mortales de vía crucis, bajo un sol de misericordia, sin otra compañía que la momentánea de alguna carreta perezosa o alguna comitiva de viajeros que es prudente esquivar para no morir de asfixia entre el polvazal que los envuelve... (Segarra y Juliá, 1907, pp. 511-512).

Los empréstitos señalados con antelación, constituyeron una respuesta estatal ante las presiones de empresarios deseosos de concluir la obra ferroviaria. Finalmente, en 1910 corrió por primera vez el tren hacia el Pacífico, su inauguración llegó a cumplir una "función redentora", cuyo cometido más visible fue llegar a convertirse en un ente regulador económico por medio del establecimiento de tarifas reducidas con respecto a la Northerm (Ulloa, 1998, p. 82). 
El Ferrocarril al Pacífico fue un proyecto enteramente nacional, dirigido por el Estado desde su construcción; sin embargo no estuvo exento de vicisitudes, que auguraban a la postre, la crisis permanente de la institución -como lo afirma Botey (1999)- a continuación se abordan las más importantes.

a) El financiamiento y las condiciones climáticas, desde un inicio de la etapa constructiva se convirtieron en grandes desafíos por vencer; como sucedió con los continuos derrumbes en Cambalache.

b) Pese a los clamores de los empresarios cafetaleros, ansiosos de contar con una ruta hacia el puerto del Pacífico, otros sectores integrados por carreteros, mostraron su reacia oposición al considerar esta vía como una amenaza a su propio trabajo como transportistas.

c) Aparte de quienes llevaban el café en carretas, con destino al puerto de embarque, se sumaron a ellos la Northern Co., concesionaria de la ruta del Caribe, quien encontró en la reducción de las tarifas y en la implementación de viajes directos, la estrategia de atacar la naciente empresa de transporte nacional.

d) Como se observará luego, el nuevo ferrocarril tuvo que hacer frente al cambio tecnológico. Las primeras locomotoras pronto quedaron rezagadas en cuanto a su alimentación energética, la potencia de arrastre y a la velocidad; de cara a las necesidades crecientes del transporte, haciendo inevitable la modernización (Ulloa, 1997, p. 99-100; Botey, 1999, p. 146 y subsiguientes).

No obstante las limitaciones anteriores, aún inconcluso, el Ferrocarril al Pacífico ofrecía atracciones muy bien resaltadas por los dos viajeros ibéricos antes mencionados, que decidieron realizar el viaje ente San José y Orotina en 1907, en lo que comprendía la primera sección de la construcción de la obra. Luego de tomar el tren a las 8:30 de la mañana arribaron a Santo Domingo a las once. Según su testimonio, la ruta no deba envidiar nada a la del Atlántico en cuanto al paisaje, la agreste naturaleza cruzada por el convoy, y por supuesto, en la obra de infraestructura monumental: "...el tendido sobre el Río Grande es simplemente una maravilla de atrevimiento diremos "de mecánica», y puede figurar con toda dignidad en el catálogo de las obras maestras de este género" (Segarra y Juliá, 1907, p. 510). 
Los españoles añaden además anotaciones acerca de la sinuosidad del trayecto: "...un culebreo endiablado al través de un paisaje montuoso sobre toda ponderación describiendo atrevidas rúbricas complicadísimas, faldeando cerros y bordeando precipicios..." (Segarra y Juliá, 1907, p. 510).

Con la obra ferroviaria terminada se facilitó el proceso de poblamiento, junto con la colonización agraria de las zonas aledañas a la vía férrea con destino al Pacífico Central merced a la construcción de caminos conducentes al entronque con el ferrocarril. Así, carretas, cargadas de maíz, frijoles y café y otros abastos, empezaron a transitar las nuevas rutas con el consiguiente establecimiento de conexiones con circuitos comerciales organizados en torno a localidades como Turrúcares, un lugar que llegó a desempeñar un importante papel gracias a la realización de ferias de granos de la década de 1930 (León, 2012, p. 189; León y Peters, 2019, p. 38; Ulloa, 1997, pp.128-130).

Y con respecto al lugar de destino final de tren, y su impacto en el puerto del Pacífico, Arabela Valverde indica,

Con la conclusión de esta obra, la ciudad de Puntarenas vino a tener un punto a su favor en cuanto al desarrollo logrado en las primeras tres décadas del siglo XX. Una vez que el ferrocarril entra en funcionamiento, trajo consigo grandes beneficios al lugar; por ejemplo, una mayor afluencia de personas que se trasladaban a "veranear"... (Valverde, 2008, p. 29).

\section{La modernización: electrificar el ferrocarril}

Uno de los grandes retos enfrentados por el ferrocarril, inaugurado en 1910, fue de índole energética. Al principio, las locomotoras de vapor se alimentaban de leña, combustible riesgoso, responsable de incendios. Además se utilizaba el carbón mineral y el petróleo crudo, sustancias fósiles de difícil obtención en los tiempos aciagos de la Primera Guerra Mundial (Ulloa, 1997, p. 100-102; Botey, 1999, p. 146).

Adicionalmente, las máquinas que utilizaban este tipo de energía, paulatinamente iban quedando rezagadas, por cuanto ya no eran tan eficientes en términos de velocidad y de capacidad de arrastre de carga. En el decenio de 1920, el Estado empezó a mirar con preocupación estas condiciones desventajosas del ferrocarril, y optó entonces por tomar las medidas necesarias de cara a modernizar dicho medio de transporte. 
La alternativa implementada se cifró en el proyecto de electrificación, capaz de dotar de un impulso decisivo a esta empresa estatal. Las obras se realizaron entre 1926 y 1930, bajo las administraciones de Ricardo Jiménez Oreamuno (1924-1928) y Cleto González Víquez (1928-1932). La empresa contratada para la realización del proyecto fue la Allgemeine Elektricitaets Gesellschaft (AEG), a quien además se le encomendó la renovación de las comunicaciones telegráficas y telefónicas (Ulloa, 1997, p. 105).

La inauguración del ferrocarril eléctrico se realizó en 1932, aunque se finalizó dos años antes; esto luego de que se pusieran al día y se integraran todos los sistemas electromecánicos. La culminación de esta etapa de modernización consta en una placa conmemorativa, ubicada en los jardines de la estación principal de San José, que reza así: "La electrificación del Ferrocarril al Pacífico instauró una nueva etapa en el desarrollo y progreso de Costa Rica...".

Durante esa misma década se remató el capítulo iniciado con la electrificación. La construcción de una nueva terminal fue el nuevo proyecto por comenzar. Para dicha misión, el arquitecto José Francisco Salazar fue el encargado del diseño del nuevo edificio que sustituiría el antiguo construido en una planta de un solo nivel con corredor perimetral, techado con láminas de hierro galvanizado; ubicado en el extremo sur de la calle 2, en una propiedad de casi siete hectáreas. El nuevo proyecto de infraestructura, inaugurado en 1941, con su respectivo andén de pasajeros, supuso la renovación total de la modesta edificación al utilizar el lenguaje art-decó, con sus esquinas redondeadas y con una planta seccionada en tres cuerpos; cuya parte central contiene un imponente vestíbulo y el acceso a la planta superior por medio de una soberbia escalinata central que se bifurca en dos hacia el este y al oeste (Fernández, 2016, p. 103-105).

Además de este edificio, se construyeron cinco grandes talleres, con vista hacia el este, uno central y dos laterales en cada costado; en el frontón de la edificación central figura lo siguiente: "Administración Cortés", seguida por una silueta del escudo de Costa Rica, y luego, los años de su gobierno, "1936-1940". 
Imagen 3. Estación del Ferrocarril al Pacífico de San José

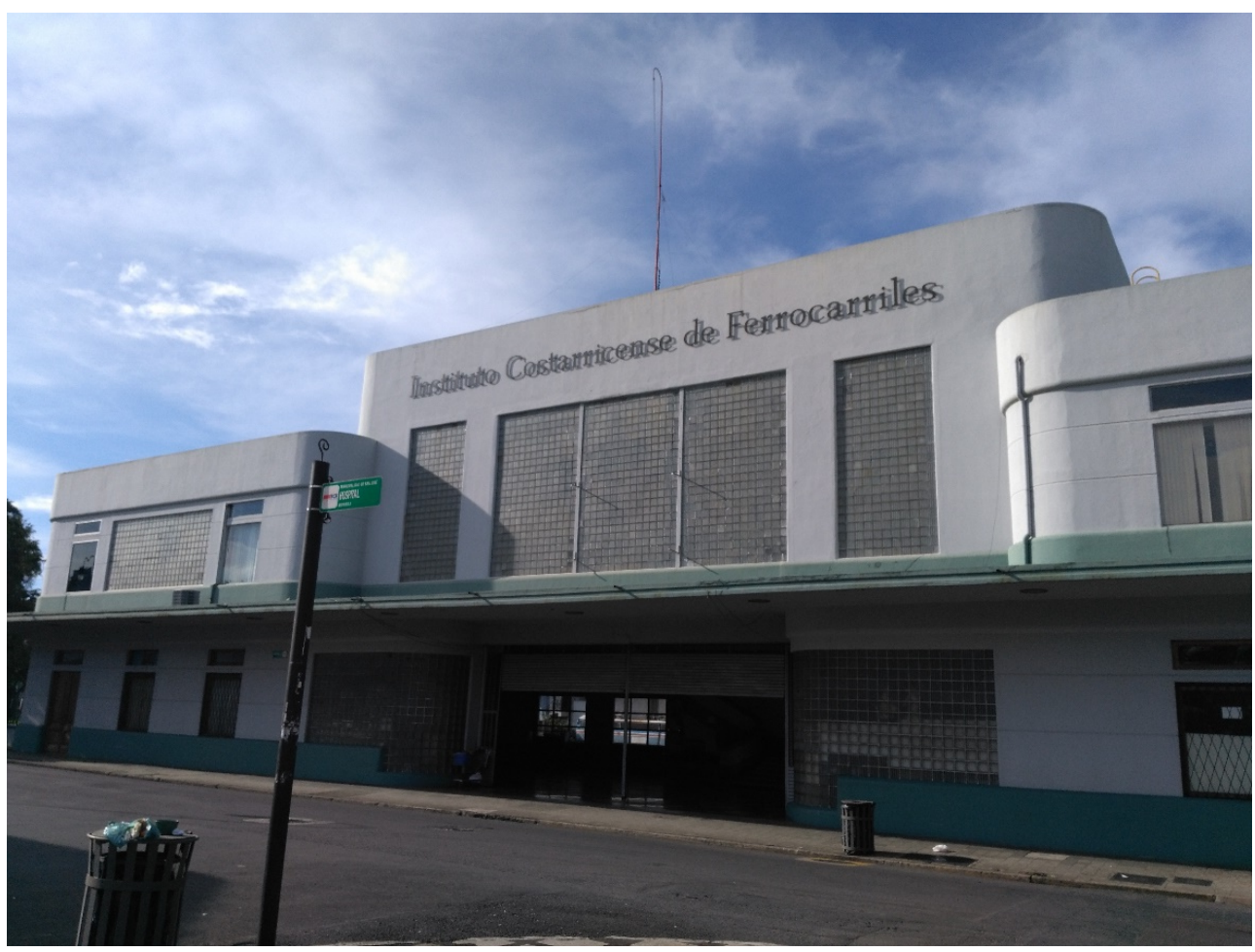

Fuente: Fotografía tomada con fines didácticos por Javier Agüero.

Imagen 4. Frontón de la tercera bodega. Estación del Ferrocarril al Pacífico de San José

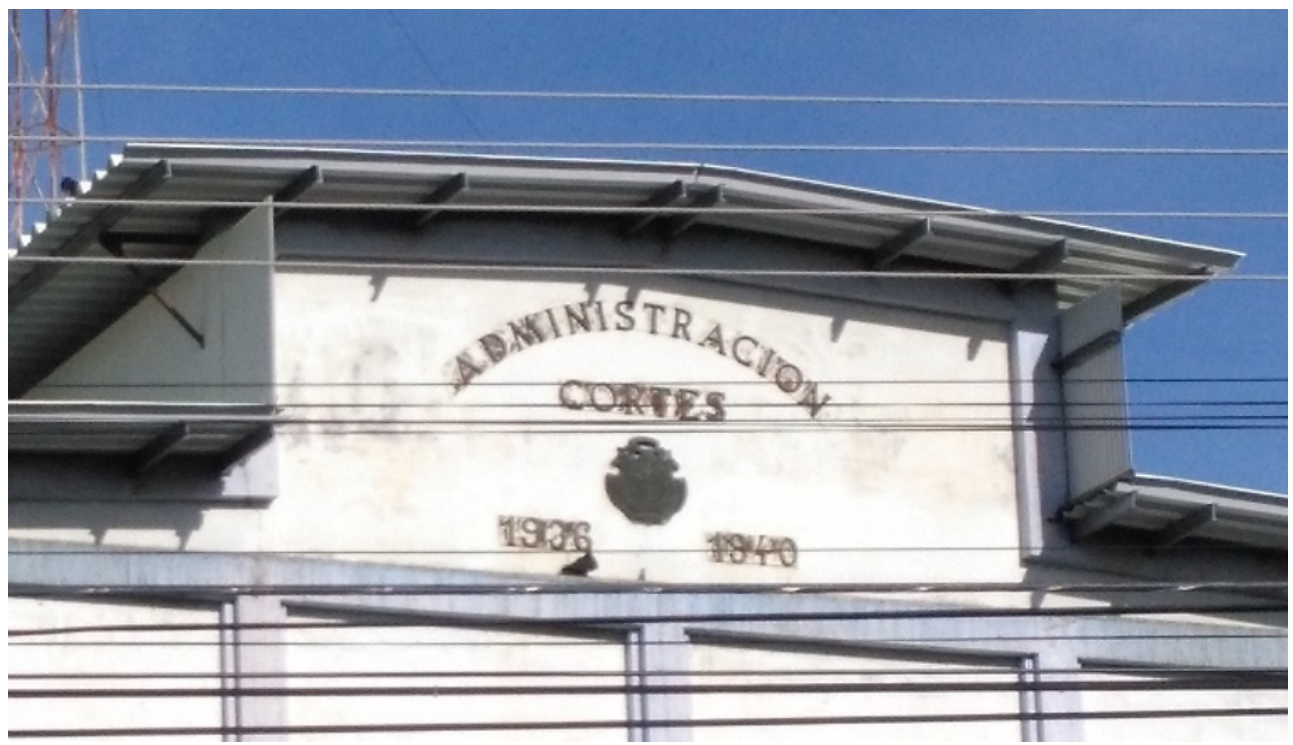

Fuente: Fotografía tomada con fines didácticos por Javier Agüero. 
De acuerdo con Rosa Elena Malavassi (2014), el establecimiento de esta estación en terrenos baldíos de la Municipalidad de San José supuso todo un hito al llegar a constituir el foco del desarrollo de actividades económicas propias del ferrocarril como de aquellas asociadas como aserraderos, producto de la llegada de madera procedente del Pacífico. Además de concentrar un centro de poblamiento de quienes ofrecían sus servicios en tales quehaceres (Malavassi, 2014, pp. 117-118).

Para el decenio de 1950, los talleres del Ferrocarril al Pacífico, por sus propias dimensiones, cumplieron una importancia trascendental tanto en las labores propias al mantenimiento de las locomotoras y de los vagones, como en el hecho de ofrecer servicios a la industria de la metalmecánica, caracterizada por la realización de trabajos de construcción o reparación de piezas de gran tamaño (Sáenz, Arroyo y Montero, 2016, p. 141).

En la amplitud de la propiedad de la empresa ferroviaria estatal, aún hoy se pueden encontrar en sus jardines: poyos, con respaldares estampados con el emblema de FE al P; una fuente hexagonal, cubierta de lirios; un busto, ocultado por un árbol, dedicado a Rafael Yglesias Castro, gobernante responsable del inicio de la construcción del ferrocarril; y tres locomotoras en exhibición, dos de carbón y una eléctrica, esta última en lamentables condiciones de conservación.

Imagen 5. Fuente hexagonal.

Estación del Ferrocarril al Pacífico de San José

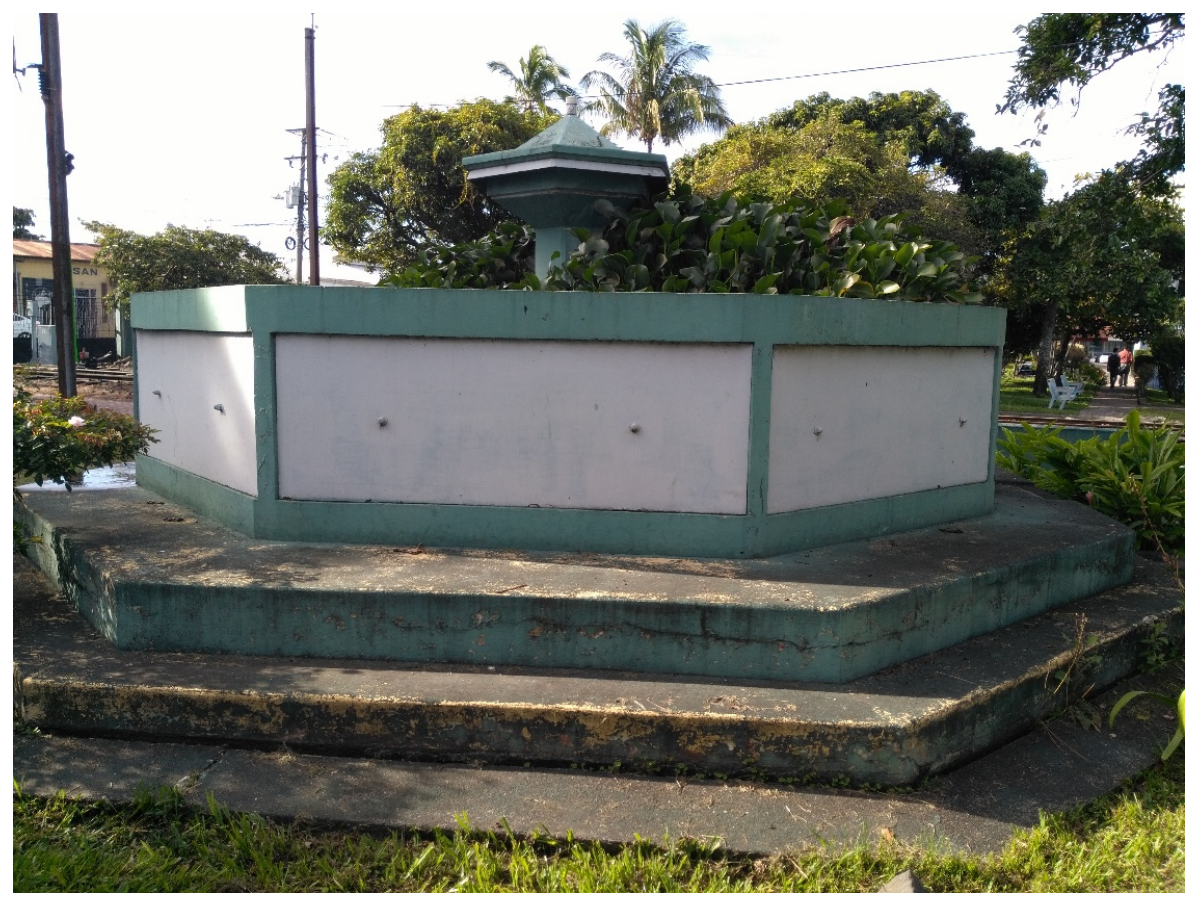

Fuente: Fotografía tomada con fines didácticos por Javier Agüero. 


\section{Los caballos de acero}

Las primeras locomotoras que realizaron el recorrido por la vía recién construida, hacia el puerto del Pacífico, fueron las de carbón; que como se anotó anteriormente también podían ser alimentadas por leña o por petróleo crudo. Las dos máquinas más llamativas son María Cecilia y Gandoca. Al respecto Guillermo Santana, expresidente ejecutivo del INCOFER y Cristina Salas, arquitecta del Centro de Conservación e Investigación del Patrimonio Cultural, describen las características de estas dos locomotoras, a propósito del proceso de restauración de ambos equipos en 2016.

-María Cecilia. De fabricación estadounidense en 1898 por parte de Dickson Manufacturing Company. Solo existe otro ejemplar completo en la antigua hacienda azucarera Enterprise Louisiana, EUA. Esta locomotora rotulada en su parte frontal con el número 1, al principio prestó servicio para la Northern Railway y luego, a partir de 1910, transportó mercancías y pasajeros hacia el Pacífico en un itinerario que se dilataba entre diez y doce horas, frente a seis u ocho días que demoraba el viaje en carreta.

Imagen 6. Locomotora de vapor María Cecilia.

Estación del Ferrocarril al Pacífico de San José

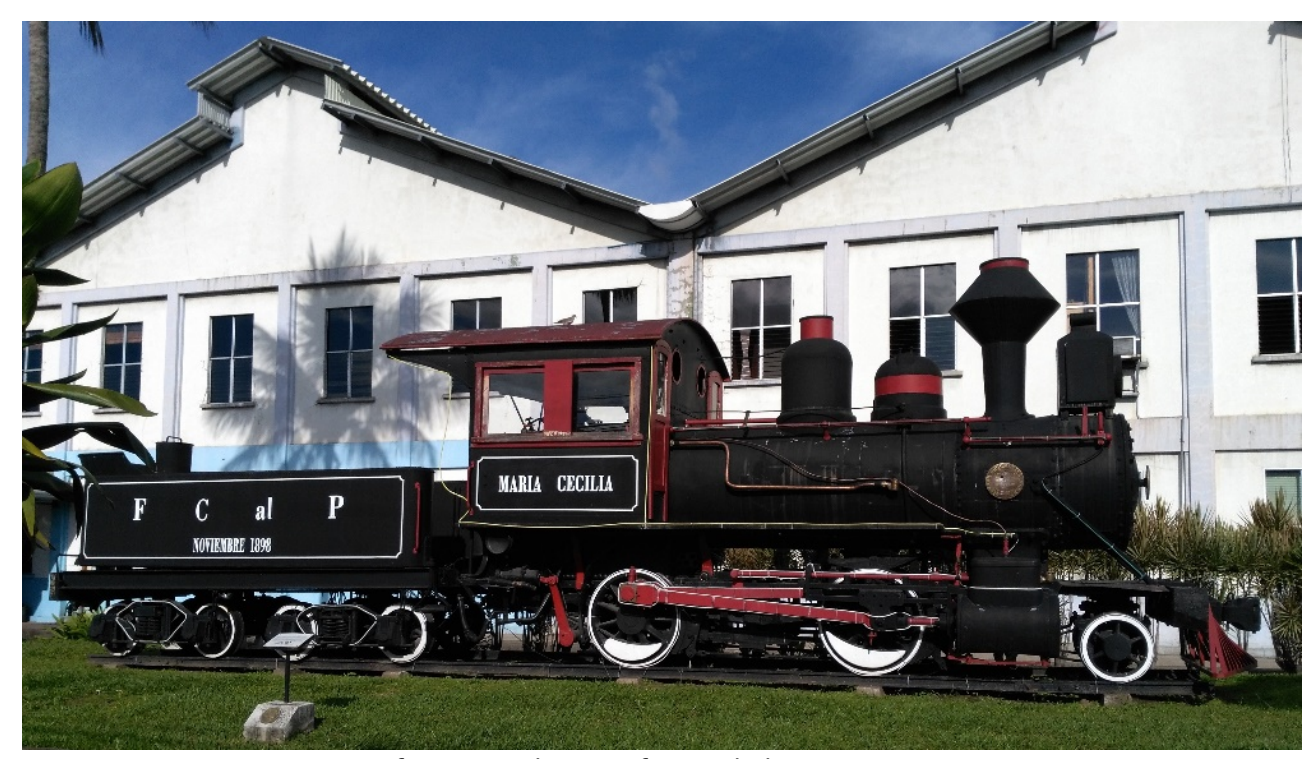

Fuente: Fotografía tomada con fines didácticos por Javier Agüero. 
-Gandoca. Rotulada al frente y a los costados con el número 14. Fabricada cerca de 1885, en Estados Unidos por Baldwin Locomotive Works. Existen ejemplares en Australia, México y Cuba. Inicialmente utilizada por la empresa concesionaria del Ferrocarril al Atlántico al transporte de madera, específicamente en la sección del Caribe sur, sobre todo al trasiego clandestino de esta materia prima con destino a Panamá. Dicha práctica ilegal motivó a las autoridades a trasladarla, a manera de castigo, para prestar servicio con destino al Pacífico (Solano, 2016; Canal 11, 2016).

Imagen 7. Locomotora de vapor Gandoca.

Estación del Ferrocarril al Pacífico de San José

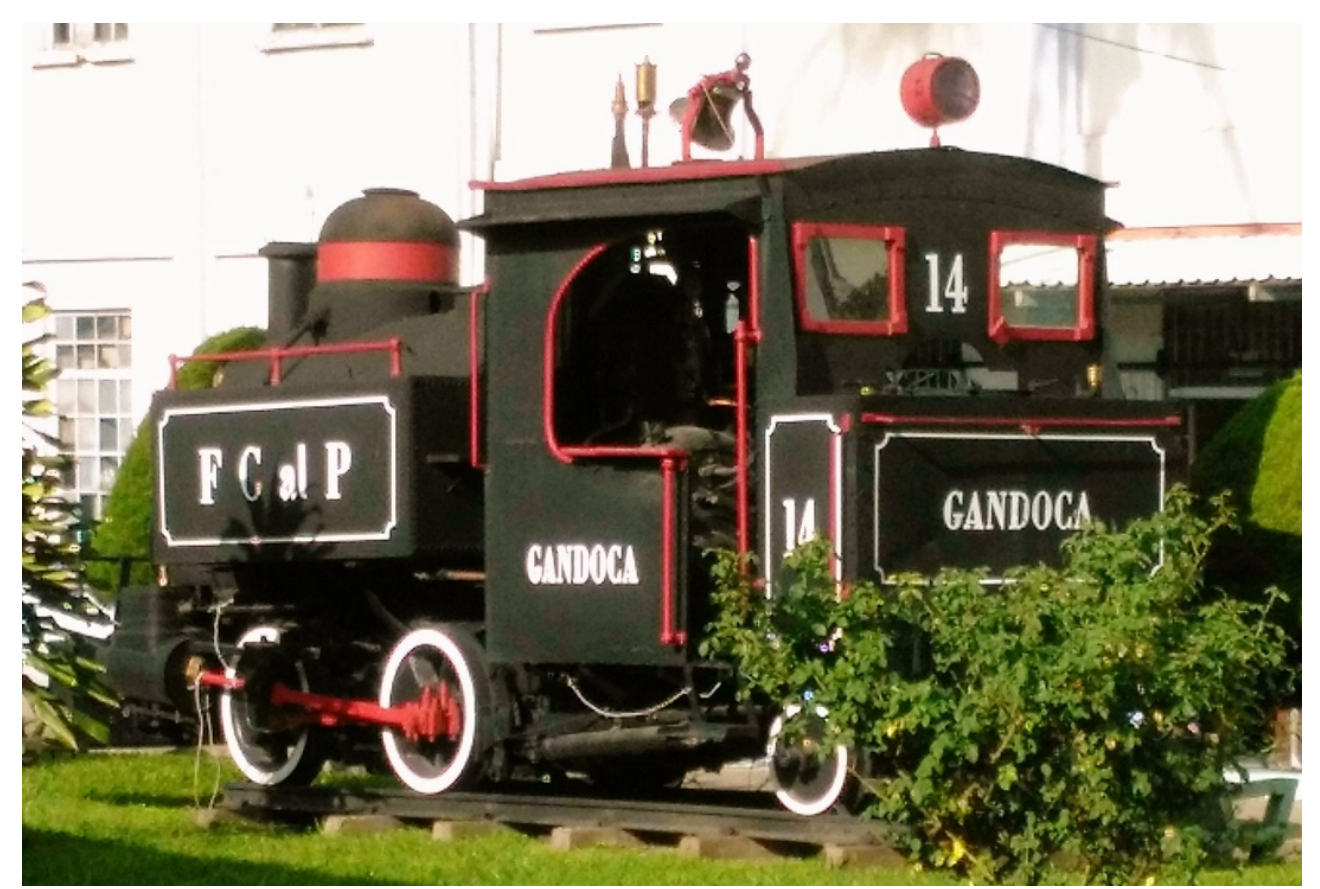

Fuente: Fotografía tomada con fines didácticos por Javier Agüero.

Con la modernización, generada por la sustitución de la energía motriz del ferrocarril por electricidad, se hizo necesaria la adquisición de nuevas locomotoras. De Alemania, concretamente de la casa fabricante AEG -la misma encargada del proyecto de electrificación-, se importaron las primeras máquinas para recorrer el tramo entre San José y Puntarenas. Se cerró así el ciclo de las locomotoras antiguas de carbón y se pasó a un nuevo sistema ferroviario más 
eficiente, por la reducción en los costos energéticos, y con mayor capacidad de carga y, desde luego, se aumentó la velocidad con la consiguiente reducción del tiempo de los recorridos. Los ejemplares más conocidos de esta primera generación de locomotoras eléctricas se identifican con los números 3, 10, 22, 125 y 127 . La primera de ellas, pintada de negro, ubicada en el costado norte de los predios de la Estación del Ferrocarril al Pacífico, y la última, luce los colores de la bandera tricolor, descansa contiguo a la Estación de Río Grande en Atenas.

Como evidencia del esfuerzo estatal en la adquisición de equipo moderno para la época, en los jardines de la Estación al Pacífico, frente a la locomotora eléctrica número 3, se colocó en 1986, una placa alusiva al equipo, "...Una muestra de ello lo constituyó esta locomotora eléctrica construida en Alemania en el año 1929 que aquí se conserva como reliquia corriéndose el primer tren eléctrico el 8 de abril 1930.".

Imagen 8. Locomotora eléctrica número 3.

Estación del Ferrocarril al Pacífico de San José

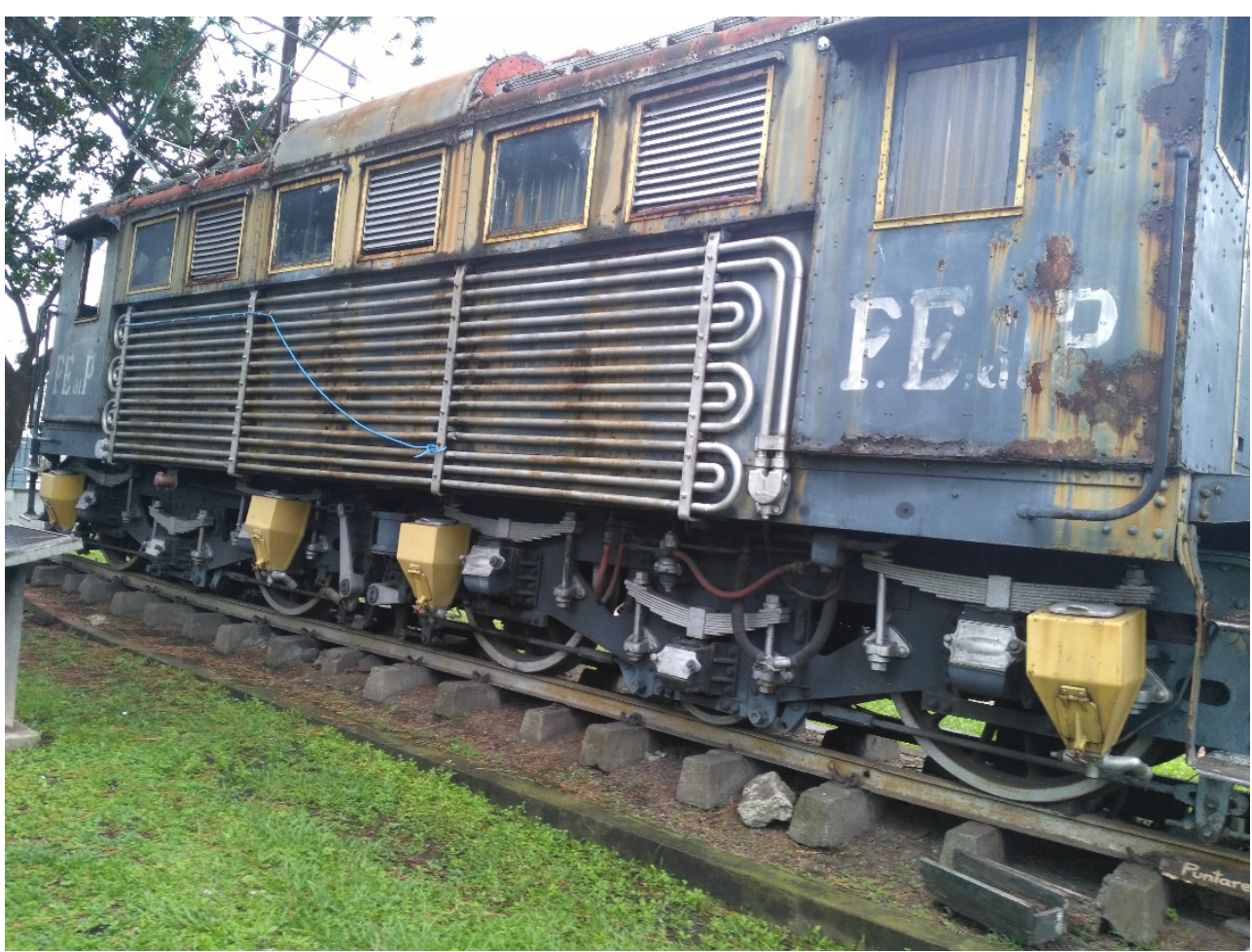

Fuente: Fotografía tomada con fines didácticos por Javier Agüero. 
Veinticinco años más tarde, en el segundo lustro de 1950, el gobierno de José Figueres Ferrer (1953-1958), deseoso de elevar la producción nacional, tomó la iniciativa de remozar el Ferrocarril Eléctrico al Pacífico, lo convirtió en una institución autónoma (Pérez, 1997, pp. 147 y 150) y adquirió cuatro nuevas locomotoras fabricadas por la casa Henschel Siemens, desembarcadas en el muelle de Puntarenas en 1957. Entre los cuatro caballos de acero, ejemplares de la tecnología de punta de aquellos años, estaba la máquina 130, La 130, reseñada al inicio de este ensayo; las cuatro pintadas con los colores de la bandera costarricense, eran las número 131, 132 y 133, y por supuesto, La 130 (Patrimonio Cultural de Orotina, 2016).

Imagen 9. Locomotora eléctrica Siemens 130, Orotina

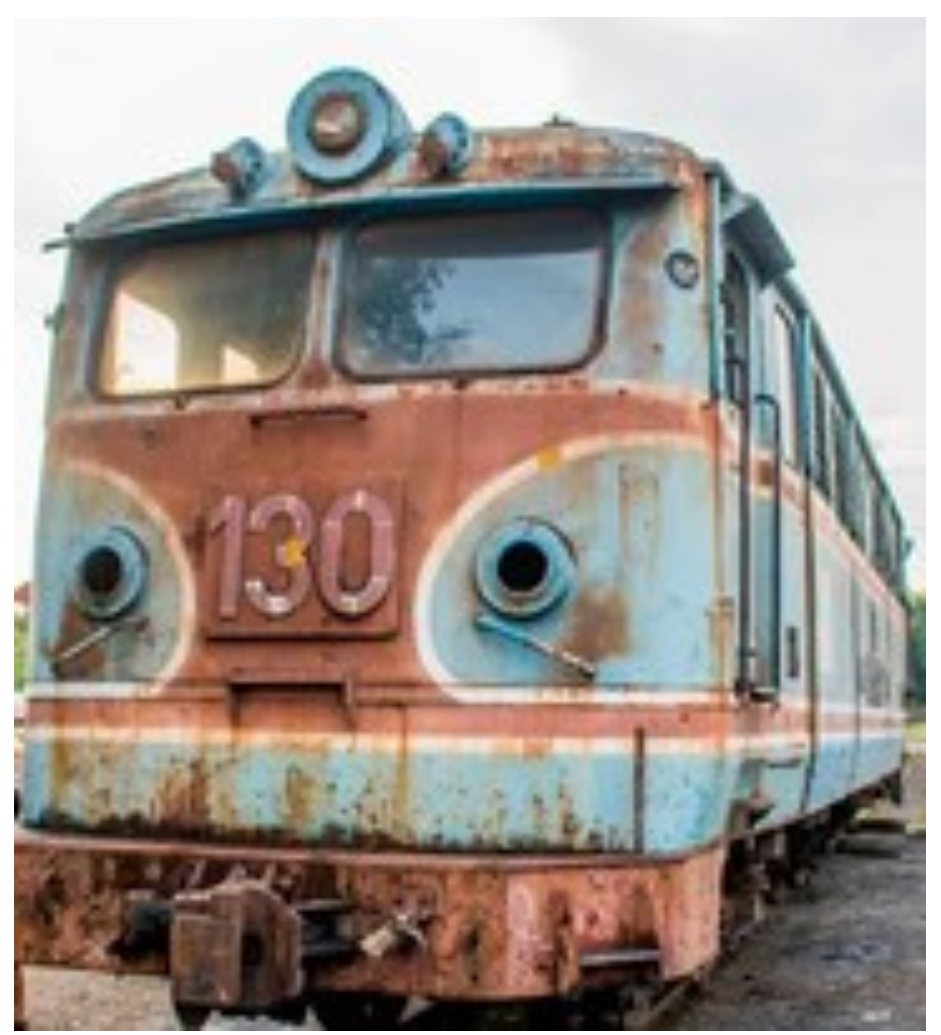

Fuente: Fotografía tomada con fines didácticos por Javier Agüero.

Con un frente redondeado, dos focos laterales y un reflector en la sección superior central, estas locomotoras prometían consolidar el camino iniciado en el decenio de los treinta con el proyecto de modernización. De ahí que en una estampilla de 1959, figurara una locomotora Siemens, alusiva al proyecto de electrificación del Ferrocarril al Pacífico (Corrales, 2016). 
Indudablemente, el símbolo del progreso costarricense estuvo encarnado en el Ferrocarril al Pacífico, institución netamente estatal que surgió en un momento clave de la historia de Costa Rica; cuando el Estado mismo ensayaba un régimen liberal de bienestar de corte benefactor, más distante del liberalismo decimonónico (Viales, 2009, pp 71-73). En este contexto se realizaron encomiables esfuerzos por construir una ruta hacia el Pacífico que posibilitara el transporte del café a Puntarenas para así obviar las limitaciones impuestas por la compañía bananera, propietaria de la empresa ferrocarrilera prestataria del transporte hacia el Caribe. Ese fue justamente el cometido de esta empresa estatal que para los albores de la década de 1930, había sido remozada merced al tesón de quienes tomaron en serio el proyecto de la electrificación conduciendo a la empresa ferroviaria por la senda de la actualización al servicio de sus usuarios. Estos logros se convirtieron en atributos del Ferrocarril Eléctrico al Pacifico. Eran cuatro, y así lucen en una silueta alusiva al escudo de la República de Costa Rica, estampada en el piso de mosaico del vestíbulo de la estación de San José: rapidez, economía, seguridad y eficiencia.

Imagen 10. Emblema estampado en el mosaico. Estación del Ferrocarril al Pacífico de San José

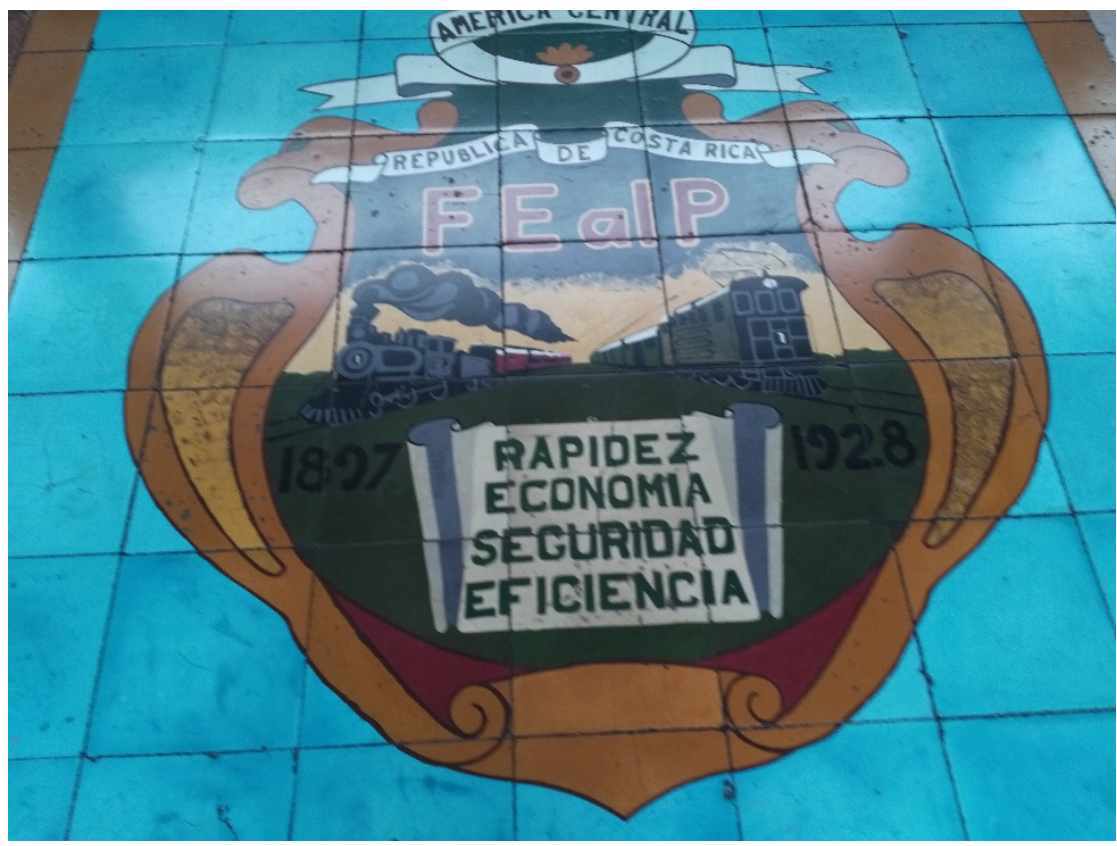

Fuente: Fotografía tomada con fines didácticos por Javier Agüero. 


\section{Epílogo}

En 1981, durante el gobierno de Rodrigo Carazo Odio (1978-1982), se importaron de Alemania doce locomotoras eléctricas, fabricadas por la casa Acec Aeg-Telefunken Alsthom Brow Bover Siemens Mte Beltort. Cada una de esas nuevas máquinas contaba con un sistema de cincuenta ciclos y con una potencia capaz de desplazar 40 vagones en terrenos planos y 26 vagones en la sinuosidad de los caminos montañosos. (Formoso y Loaiza, 2008, p. 8 A). Con esta adquisición, se tenía en mente reforzar a las locomotoras Siemens adquiridas en el decenio de 1950, en virtud de que el gobierno de Carazo deseaba brindar un nuevo impulso al sistema de ferrocarriles agrupados en ese entonces por Ferrocarriles de Costa Rica, FECOSA, institución fundada en 1977.

Las nuevas locomotoras venían a recorrer el tramo recién electrificado por ese gobierno ubicado, entre Moín y río Frío, en el Caribe, y por otro lado, ponerlas en servicio en la ruta del Pacífico; abordada en este ensayo, empezada a construir en 1897 y electrificada a inicios de los años treinta. Los resultados concretos de esta inversión en dólares, responsable de lo que fuera la última compra de máquinas eléctricas, quedarán por tratarse en un trabajo posterior, tan solo se puede adelantar que el Instituto Costarricense de Ferrocarriles (INCOFER), institución fundada en 1985, que sustituyó a FECOSA, devino en una situación caótica hasta su cierre técnico en la década de 1990.

Entre tanto, con el paso de los años, en enero de 2000, con ocasión de celebrarse una edición más de los carnavales de Puntarenas, se anunciaba con gran pompa, que seis vagones salían con rumbo al Pacífico, desde la terminal diseñada por el arquitecto José Francisco Salazar. No obstante, quienes decidieron evocar el pasado, lleno de recuerdos de los gallos de papa y de gallina achiotada, no eran transportados por una locomotora eléctrica; en su lugar, una máquina impulsada por la combustión de diésel sería la responsable de llegar a su destino. Este viaje del recuerdo de los turistas dispuestos a disfrutar del sol y de la playa se asemeja en algo al itinerario seguido por la máquina 130, descrito al inicio de este escrito. Ambos periplos evocan un pasado y una memoria compartida por una sociedad que supo labrar un destino, surcado por ruedas de acero, para llevar el café a los mercados compradores extranjeros, para hacer posible el desarrollo de los pueblos como Orotina, y por supuesto, para que las familias tuvieran un rato de esparcimiento en las soleadas arenas puntarenenses. Mientras tanto La 130, hace dos años permanece en el cantón de la frutas, y espera ponerse en operación algún día, 
para mostrar al público su poder; no obstante por el momento resulta imposible, por su estado de deterioro, y porque la vía férrea hacia el Pacifico no cuenta con tendido eléctrico desde hace veinticinco años.

\section{BIBLIOGRAFÍA}

Araya, C. (1982). Historia económica de Costa Rica (1821-1971). San José: Editorial Fernández Arce.

Botey, A. M. (1999). "El Ferrocarril al Pacífico: un ente de regulación en crisis permanente (1880-1972)". Anuarios de Estudios Centroamericanos. (25), 139-157.

Bucheli, M. \& Read, I. (2017). Los barcos bananeros y los alimentos infantiles: el plátano en la historia de los Estados Unidos. Carlos Marichal, Steven Topik y Zephyr Frank (coordinadores). De la plata a la cocaína. Cinco siglos de historia económica de América Latina, 1500-2000. (pp. 287-320). México: Fondo de Cultura Economica-El Colegio de México.

Canal 11, Informe 11. (4 de marzo de 2016). La restauración de dos antiguas locomotoras. [Vídeo]. Recuperado de https://www.youtube.com/watch?v=EacsqNox8AA

Canal 11, Informe 11. (24 de agosto de 2014) Locomotoras AEG alemanas Costa Rica. [Vídeo]. Recuperado de https://www.youtube.com/watch?v=k_UGhFu4GPw

Cardoso, C. \& y Pérez, H. (1983). Centroamérica y la economía occidental (15201930). San José: ECR-EUCR.

Cardoso, C. \& Pérez, H. (1982). Historia económica de América Latina. 2 Economías de exportación y desarrollo capitalista. Barcelona: Crítica.

Castro, K. (28 de abril de 2017). "Orotina renovará locomotora alemana". Crhoy.com. Recuperado de https://www.crhoy.com/nacionales/orotina-renovarahistorica-locomotora-alemana/

Corrales, J. (30 enero de 2016). Locomotoras Siemens alemanas Costa Rica. [Vídeo]. Recuperado de https://www.youtube.com/watch?v=8UAzdi4ppBc 
Fernández, A. (2016). XV. Para ir al Puerto. La estación al Pacífico. En A. Fernández. Pasado construido: crónicas sobre arquitectura histórica josefina. San José: Editorial Costa Rica.

Formoso, A. \& Loaiza, V. (14 de julio de 2008). "Incofer desaprovecha 11 locomotoras." La Nación. p. 8 A.

Hall, C. (1982). El café y el desarrollo histórico-geográfico de Costa Rica. San José: ECR.

Jara, A. (2014). Finanzas públicas y crecimiento del Estado: un siglo de ingresos y gastos estatales en Costa Rica 1870-1980. Historia económica de Costa Rica en el siglo XX: Tomo 1. Crecimiento y las políticas económicas. (pp. 393-438). San José: IICE, CIHAC, Escuela de Historia.

León, J. (2016). Historia económica de Costa Rica en el siglo XX. Tomo II: La economía rural. San José: IICE, CIHAC, Escuela de Historia.

León, J.; Arroyo, N. \& Montero, A. (2016). Historia económica de Costa Rica en el siglo XX. Tomo III: La industria en Costa Rica en el siglo XX. San José: IICE, CIHAC, Escuela de Historia.

León, J. \& Peters, G. (2019). Historia económica de Costa Rica en el siglo XX. Tomo IV: El comercio y los mercados en Costa Rica. San José: IICE, CIHAC, Escuela de Historia.

Malavassi, R. E. (2014). La vivienda de madera de los barrios Luján-El Cerrito y barrio Keith (1910-1955). Un análisis histórico de la imagen urbana y la arquitectura habitacional. Tesis de maestría en Historia, Sistema de Estudios de Posgrado. Universidad de Costa Rica.

Molina, C. (2005). Y las mulas no durmieron... Los arrieros en Costa Rica. Siglos XVI al XIX. San José: EUNED.

Murillo, C. (1995). Identidades de Hierro y Humo: La construcción del Ferrocarril al Atlántico 1870-1890. San José: Porvenir.

Noriega, F. (1923). Diccionario geográfico de Costa Rica. San José: Imprenta Nacional. 
Patrimonio Cultural de Orotina. (24 de marzo de 2016). Campaña Salvemos la 130. [Vídeo]. Recuperado de https://www.youtube.com/watch?v=aMFxLPlzOls

Pérez, H. (1997). Breve historia contemporánea de Costa Rica. México: Fondo de Cultura Económica.

Quesada, R. (1983). Ferrocarriles y crecimiento económico: El caso de la Costa Rica Railway Company, 1871-1905. Anuarios de Estudios Centroamericanos. (9): 87-119.

Segarra, J. \& Juliá, J. (1907). Excursión por América, Costa Rica. San José: Imprenta de Avelino Alsina.

Solano, A. (17 de febrero de 2016). "Locomotoras recuperan su atractivo centenario." La Nación. Recuperado de https://www.nacion.com/elpais/patrimonio/locomotoras-recuperan-su-atractivocentenario/SIYFZU5CLVGIZEEVDRKK6DR63Q/story/

Steward, W. (1991). Keith y Costa Rica. San José: ECR.

Ulloa, H. (1997). El Ferrocarril Costarricense al Pacífico: construcción e incidencias (1897-1932). San José: ECR.

Ulloa, H. (1998). "El Ferrocarril Costarricense al Pacífico: Baluarte de la economía Nacional (1897-1935)." Revista de Ciencias Sociales, (80), 77-86.

Valverde, A. (2008). La ciudad de Puntarenas: Una aproximación a su historia económica y social, 1858-1930. San José: SIEDIN.

Viales, R. (2009). El régimen liberal de bienestar y la institucionalización de la pobreza en Costa Rica". Ronny Viales (edit). Pobreza e historia en Costa Rica. Determinantes estructurales y representantes sociales del siglo XVII a 1950. San José: EUCR. 